\title{
OPEN Identifying thresholds in the impacts of an invasive groundcover on native vegetation
}

\author{
Luke S. O'Loughlin ${ }^{1 凶}$, F. Dane Panetta² \& Ben Gooden ${ }^{1}$
}

Impacts of invasive species are often difficult to quantify, meaning that many invaders are prioritised for management without robust, contextual evidence of impact. Most impact studies for invasive plants compare heavily invaded with non-invaded sites, revealing little about abundance-impact relationships. We examined effects of increasing cover and volume of the non-native herbaceous groundcover Tradescantia fluminensis on a temperate rainforest community of southern Australia. We hypothesised that there would be critical thresholds in $T$. fluminensis abundance, below which the native plant community would not be significantly impacted, but above which the community's condition would degrade markedly. We modelled the abundance-impact relationship from 83 plots that varied in $T$. fluminensis abundance and landscape context and found the responses of almost all native plant indicators to invasion were non-linear. Native species richness, abundance and diversity exhibited negative exponential relationships with increasing $T$. fluminensis volume, but negative threshold relationships with increasing $T$. fluminensis cover. In the latter case, all metrics were relatively stable until cover reached between 20 and $30 \%$, after which each decreased linearly, with a $50 \%$ decline occurring at $75-80 \%$ invader cover. Few growth forms (notably shrubs and climbers) exhibited such thresholds, with most exhibiting negative exponential relationships. Tradescantia fluminensis biomass increased dramatically at $>80 \%$ cover, with few native species able to persist at such high levels of invasion. Landscape context had almost no influence on native communities, or the abundance-impact relationships between $T$. fluminensis and the plant community metrics. Our results suggest that the diversity of native rainforest community can be maintained where $T$. fluminensis is present at moderate-to-low cover levels.

Invasive non-native plants negatively impact native species, communities and ecosystems ${ }^{1,2}$, yet the ecological consequences of many invaders remain under-quantified ${ }^{3-5}$. Reasons for this include both practical considerations, such as management action prioritisation under limited resources ${ }^{6,7}$ and research limitations, such as inconsistent definitions, study designs, and theories for understanding invasive species impacts ${ }^{4,8,9}$. Much empirical research on invasive plant impacts assesses only the largest effect of invasion by comparing "invaded" with "uninvaded control" areas, with fewer studies considering how impacts vary across a gradient of invader abundance ${ }^{10-13}$. Invader abundance-impact relationships may be linear or nonlinear and often vary according to the impact metric under consideration ${ }^{11,14}$. In some cases, a nonlinear relationship may reveal the existence of a cover-density threshold, beyond which there is a marked decrease in an impact metric with further increases in invasive species cover (e.g. $\left.{ }^{12}\right)$.

Invader abundance-impact relationships can be mediated by the functional traits and other characteristics of the resident native species that comprise the invaded community ${ }^{10,15,16}$. For example, Gooden et al. ${ }^{12}$ observed an impact threshold of approximately $85 \%$ cover for the invasive shrub Lantana camara on native vine species richness, but a significantly lower threshold for richness of native ferns ( $\sim 30 \%$ cover $)$, indicating differential resistance to invader impacts between resident species. Similarly, Fried and Panetta ${ }^{17}$ identified a lower impact threshold for the cover of a sub-component of the community (66\% invader cover for perennial forbs) than for total vegetation cover $(86 \%)$ in response to increasing abundance of the invasive shrub Baccharis halimifolia. Identifying plant growth form impact thresholds would elucidate which components of the recipient vegetation community are most severely impacted by non-native plant invasion and hence help to identify the species that are most likely to benefit from proactive management action ${ }^{11,14}$. 
The functional response of native species to the altered conditions of an invaded ecosystem can also influence abundance-impact relationships. For example, shade-tolerant native species may benefit where an invader decreases light to the understorey, resulting in a functional shift in community composition without an overall reduction in vegetation diversity ${ }^{18,19}$. The abundance-impact relationship between an invasive plant and the functional diversity of a community may differ from the impact relationship with other more general indicators, such as native species richness ${ }^{4,19,20}$.

The abundance-impact relationship for any invasive species is likely context-specific, varying in space and time, and influenced by other habitat or landscape factors ${ }^{4,21}$. Landscape modification can drive invader impacts on native diversity by promoting non-native species abundance ${ }^{21-23}$ or amplifying invasive species' per capita effects on native vegetation ${ }^{24,25}$. For example, in a study that controlled for the presence of disturbance and invasion, Sokol et al. ${ }^{25}$ found that logging plus invasion was associated with larger, smaller, or reversed impacts on different soil properties than simply invasion alone. Therefore, it is likely that landscape contextual factors (such as disturbance) would also modulate invader abundance-impact relationships, such that the magnitude of native diversity decline in response to invasion will be greatest in certain landscape contexts.

The aim of our study was to evaluate the abundance-impact relationships of the invasive ground-cover herb Tradescantia fluminensis with native temperate rainforest vegetation across variation in landscape context. Our study landscape comprised remnant cool temperate rainforest that occurred primarily in fragmented, often linear patches along streams and roadside reserves, intermixed with anthropogenic landscape features, such as suburban dwellings, footpaths, roads, industrial infrastructure and cleared pastures used for the cultivation of crops or livestock grazing. Our hypotheses were: (1) that there would be a critical threshold in the abundance-impact relationship between $T$. fluminensis and the native plant community, below which there would be no major impact of invasion; (2) that critical thresholds in the abundance-impact relationship of T. fluminensis would vary among different native plant growth forms; and (3) that abundance-impact relationships of T. fluminensis would be influenced by landscape context. We expected that a low-to-moderate cover of T. fluminensis would need to develop before there were major changes in plant diversity, but that this threshold would be: (1) lower for plant growth forms that most directly compete with T. fluminensis (such as native spreading herbs); (2) higher for plant growth forms that may have some resistance to invasion (such as climbers or tree ferns that can grow above T. fluminensis); and (3) lower in areas closer to modified landscape features (such as roads, footpaths, and urban gardens) that could amplify the impacts of T. fluminensis.

\section{Results}

Summary of vegetation composition. A total of 91 vascular plant taxa, representing 45 families, was recorded in this study. Of these predominantly perennial species $(\sim 95 \%), 61$ were native $(\sim 68 \%), 28$ were nonnative $(\sim 31 \%)$ and two could not be identified to species level (species list provided in Appendix 3$)$. Only five species were recorded from more than one-third of plots: Tetrarrhena juncea (graminoid; present in 54\% of plots), Australina pusilla (forb; 54\%), Coprosma quadrifida (shrub; 40\%), Hackelia latifolia (herb; 37\%) and Polystichum proliferum (fern; 35\%). Most species (61\%) were rarely encountered, occurring in fewer than $5 \%$ of plots (Appendix 3).

Native species richness, relative abundance, and diversity. Tradescantia fluminensis cover and volume featured in all top-ranked models for the three native plant response variables: species richness, relative vegetation abundance and diversity $\left(\mathrm{H}^{\prime}\right)$. In all models, T. fluminensis was strongly negatively associated with each native plant response variable (Table 1). In response to increased T. fluminensis cover, native species richness, abundance and diversity $\left(\mathrm{H}^{\prime}\right)$ were all relatively stable until T. fluminensis cover reached between 20 and $30 \%$, after which the native variables decreased by $66-75 \%$ (Fig. 1a,c,e).

Native species richness and abundance also decreased significantly with increasing T. fluminensis volume, with a $50 \%$ decline in each occurring before T. fluminensis volume reached $0.5 \mathrm{~m}^{3}$ (Fig. $1 \mathrm{~b}$, d). This volume corresponded with approximately $80 \%$ cover (Fig. 2). For volume, the shape of each response curve was a negative exponential relationship. Native plant diversity $\left(\mathrm{H}^{\prime}\right)$ decreased more linearly with increasing $T$. fluminensis volume, but with greater variability in the response owing to significant interactive effects with distance to streams and footpaths (Table 1, Fig. 1f)-i.e. the magnitude of decline in diversity $\left(\mathrm{H}^{\prime}\right)$ in response to increasing $T$. $f l u$ minensis volume was greatest further away from streams and footpaths. No other landscape co-variates directly influenced any native variables (Table 1).

Non-native plants species richness was not associated with $T$. fluminensis cover (Coeff. $=-0.23,95 \%$ CI $[-0.73,0.14])$ but was negatively associated with $T$. fluminensis volume (Coeff. $-0.52, \% 95$ CI $[-0.82,-0.22]$ ) based on model averaging of top-ranked models.

Species richness and abundance of native plant growth forms. Tradescantia fluminensis cover featured in all top-ranking models for the species richness and cover abundance of the eight growth form groups. In all cases, except for native trees, increased T. fluminensis cover was negatively associated with growth-form species richness and abundance (Table 2, Fig. 3). On average, across the gradient of T. fluminensis cover, the species richness of graminoids, ground ferns, tree ferns, and spreading herbs decreased exponentially by $>50 \%$ (i.e. from approximately 1-2 to $0-1$ species per plot, Fig. 3 ). The species richness of climbers and shrubs displayed a negative threshold response, only decreasing significantly after approximately $20 \% \mathrm{~T}$. fluminensis cover was reached (Fig. 3) and approaching zero species on average per plot after T. fluminensis cover exceeded $75 \%$.

The relative abundance of graminoids, ground ferns, spreading herbs and shrubs was relatively stable until T. fluminensis cover reached approximately $20 \%$, after which it decreased significantly (Fig. 3). The species richness and relative abundance of tufted herbs were predicted to be highest at moderate levels of T. fluminensis 


\begin{tabular}{|c|c|c|c|c|c|}
\hline \multirow[b]{2}{*}{ Native response variable } & \multirow[b]{2}{*}{ Effect } & \multicolumn{2}{|l|}{ Trad cover } & \multicolumn{2}{|l|}{ Trad volume } \\
\hline & & Coefficient (95\% CI) & Statistic & Coefficient $(95 \% \mathrm{CI})$ & Statistic \\
\hline \multirow{8}{*}{ Species richness } & Intercept & $1.72(1.63,1.83)$ & 32.89 & $1.70(1.56,1.83)$ & 25.19 \\
\hline & Trad (linear) & $-4.90(-5.98,-3.82)$ & 8.86 & $-0.63(-0.81,-0.45)$ & 6.80 \\
\hline & Trad (quad.) & $-1.26(-2.16,-0.36)$ & 2.74 & & \\
\hline & Dist. to stream & $-0.04(-0.13,0.06)$ & 0.75 & $-0.09(-0.25,0.06)$ & 1.19 \\
\hline & Dist. to footpath & & & $-0.14(-0.31,0.04)$ & 1.50 \\
\hline & Dist. to forest edge & & & $0.02(-0.06,0.10)$ & 0.46 \\
\hline & Trad $\times$ stream & & & $-0.14(-0.33,0.05)$ & 1.47 \\
\hline & Trad $\times$ footpath & & & $-0.24(-0.48,0.00)$ & 1.97 \\
\hline \multirow{9}{*}{ Relative abundance } & Intercept & $2.96(2.79,3.13)$ & 33.77 & $2.87(2.67,3.06)$ & 29.32 \\
\hline & Trad (linear) & $-5.48(-6.37,-4.60)$ & 12.14 & $-0.80(-0.99,-0.62)$ & 8.46 \\
\hline & Trad (quad.) & $-1.64(-2.48,-0.81)$ & 3.88 & & \\
\hline & Dist. to garden & $-0.02(-0.16,0.05)$ & 0.42 & $-0.02(-0.21,0.04)$ & 0.42 \\
\hline & Dist. to forest edge & $0.01(-0.10,0.08)$ & 0.10 & $0.01(-0.13,0.06)$ & 0.22 \\
\hline & Dist. to footpath & & & $-0.05(-0.30,0.05)$ & 0.55 \\
\hline & Dist. to road & & & $-0.24(-0.56,0.07)$ & 1.30 \\
\hline & Trad $\times$ footpath & & & $-0.06(-0.43,0.05)$ & 0.59 \\
\hline & Trad $\times$ road & & & $-0.34(-0.81,0.11)$ & 1.34 \\
\hline \multirow{7}{*}{ Diversity $\left(\mathrm{H}^{\prime}\right)$} & Intercept & $1.51(1.37,1.64)$ & 22.07 & $1.46(1.31,1.61)$ & 22.99 \\
\hline & Trad (linear) & $-4.69(-5.43,-3.96)$ & 12.51 & $-0.64(-0.75,-0.55)$ & -14.11 \\
\hline & Trad (quad.) & $-1.41(-2.16,-0.67)$ & 3.71 & & \\
\hline & Dist. to stream & $-0.01(-0.15,0.01)$ & 0.31 & $-0.16(-0.24,-0.08)$ & -3.96 \\
\hline & Dist. to footpath & $-0.00(-0.12,0.07)$ & 0.03 & $-0.17(-0.27,-0.08)$ & -3.35 \\
\hline & Trad $\times$ stream & $-0.00(-0.14,0.02)$ & -0.08 & $-0.17(-0.26,-0.07)$ & -3.58 \\
\hline & Trad $\times$ footpath & & & $-0.21(-0.34,-0.07)$ & -3.09 \\
\hline
\end{tabular}

Table 1. Model results testing the effects of Tradescantia fluminensis foliage cover (\%), volume $\left(\mathrm{m}^{3}\right)$ and landscape predictor variables on native species richness, relative $\%$ foliage cover abundance and diversity (Shannon-Wiener Diversity Index, $\mathrm{H}^{\prime}$ ); $n=83$. Standardised regression coefficients with $95 \%$ confidence intervals and test statistic (GLMM Z-value for species richness and relative abundance, LMM t-value for diversity) from model averaging are shown for predictor variables that featured in the top-ranked models $(\triangle \mathrm{AICc}<2)$ for each native response variable (see Table S2). Bold values denote significant effects $(P<0.05)$.

cover $(\sim 50 \%)$ and lowest where T. fluminensis was either absent or dominant (Fig. 3 ). The richness and relative abundance of tufted herbs were also positively associated with increased distance from a road, and the relative abundance of graminoids was positively associated with increased distance from a stream (with a significant T. fluminensis by distance from stream interaction) (Table 2). No other significant effects of landscape factors were identified (Table 2).

\section{Discussion}

Importance of the invader abundance metric for understanding thresholds of impact on native communities. We found that invasion of T. fluminensis was strongly negatively associated with the diversity of the native cool temperate rainforest community. Native species richness, abundance and diversity all decreased to close to zero as T. fluminensis foliage increased to $100 \%$ cover. Such patterns are consistent with the general negative effects of invasive non-native plants on recipient native plant communities ${ }^{1,2}$, and particularly ground-cover invaders that have been demonstrated to competitively exclude and suppress native species ${ }^{20,26,27}$.

In correlative (non-manipulative) studies like ours, negative associations between invader abundance and the characteristics of native vegetation communities can arise from either the direct impacts of invasion on the resident community (where a reduction in native species richness is a consequence of invasion) or via an indirect mechanism, whereby some form(s) of primary vegetation disturbance precipitates native species decline and commensurate increase in invader abundance. Such 'driver-passenger' models have been explored extensively in the literature (e.g. ${ }^{28,29}$ ) and are usually tested using small-scale manipulative experiments (e.g. invader addition or invader removal studies ${ }^{16,30}$ ) or rarely with longitudinal observations (e.g. ${ }^{31}$ ). However, such experiments usually lack context at a landscape scale and are thus unable to evaluate interactive effects of invasion and large-scale disturbances on resident native communities. Observational studies like ours, undertaken at a landscape scale, are critical in contextualising broad patterns of community change in association with non-native plant invasion. In our case, we ensured that the spectrum of T. fluminensis invasion was well-represented across a gradient of landscape disturbance, and such disturbance was shown to have very little negative effect on native vegetation diversity (discussed below). The strongest predictor of diversity decline was invader cover, thus indicating that 

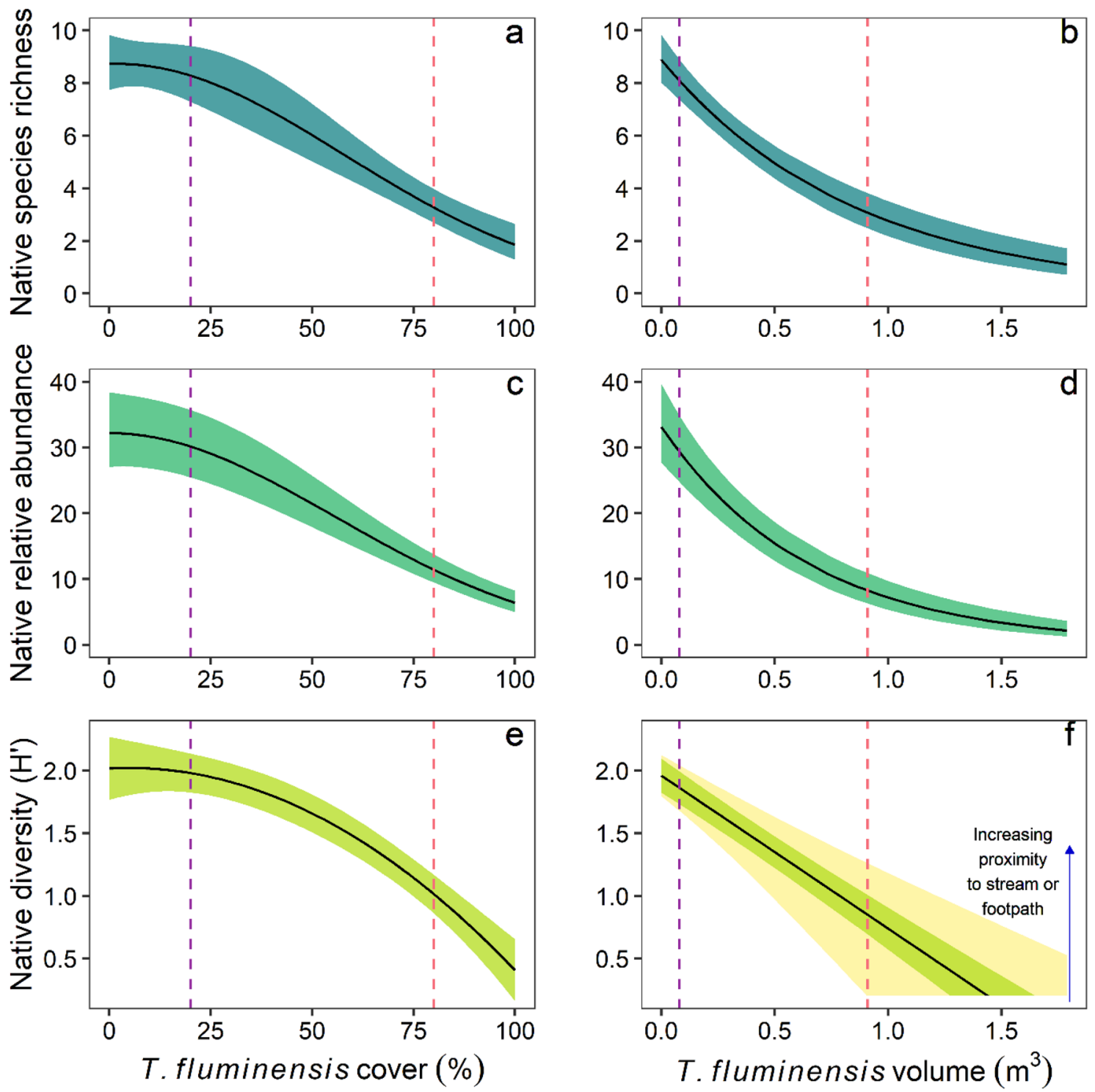

Figure 1. The response of native plant species richness (a,b), relative $\%$ foliage cover abundance (c,d), and diversity (Shannon-Wiener Diversity Index, $\left.\mathrm{H}^{\prime}\right)(\mathbf{e}, \mathbf{f})$ to increasing foliage cover $(\%)$ and volume $\left(\mathrm{m}^{3}\right)$ of Tradescantia fluminensis, measured in $2 \mathrm{~m} \times 2 \mathrm{~m}$ quadrats $(n=83)$. Vertical dotted lines represent $20 \%$ (purple) and $80 \%$ (pink) cover values for T. fluminensis. Solid black lines represent predicted values from the top ranked GLMM (richness and abundance) or LMM (diversity), bound by $95 \%$ confidence intervals. These predictions are based on averaged predicted values from all top-ranked models $(\triangle \mathrm{AICc}<2)$, with other predictor variables held at their mean values. The exception to this is the predicted response of Diversity $\mathrm{H}^{\prime}$ to $T$. fluminensis volume (f), where there was a significant interactive effect of distance from streams and footpaths with T. fluminensis. Therefore, along with predictions where these two landscape covariates are held at their mean (i.e. the solid black line in plate f), we also included the predicted $95 \%$ confidence intervals (yellow), where the magnitude of native diversity $\mathrm{H}^{\prime}$ decline is either less severe with increasing proximity to streams or footpaths (as indicated) or more severe with greater distance from streams or footpaths.

T. fluminensis invasion is driving community change. This is consistent with observations that T. fluminensis can actively invade deeply shaded, healthy, intact rainforest stands, often at great distance from forest edges.

We identified a clear and consistent impact threshold of around $20 \%$ cover abundance of T. fluminensis, below which native species richness, abundance and diversity were relatively stable but above which they all declined linearly on average by approximately $80 \%$ as $T$. fluminensis cover approached $100 \%$. This threshold based on T. fluminensis cover is markedly different from both generalised abundance-impact relationships quantified among invaders as a group and those of other invasive plants. A meta-analysis of abundance-impact relationships for all invasive species (plants and animals) by Bradley et al. ${ }^{10}$ revealed predominately linear relationships, and no density-dependence thresholds for impacts of invasive plants on native plants. Empirical tests of abundance-impact relationships for invasive plants vary considerably, from having no relationship with native species ${ }^{32}$, linear declines ${ }^{17}$, or much higher thresholds of cover before native species are impacted, such 


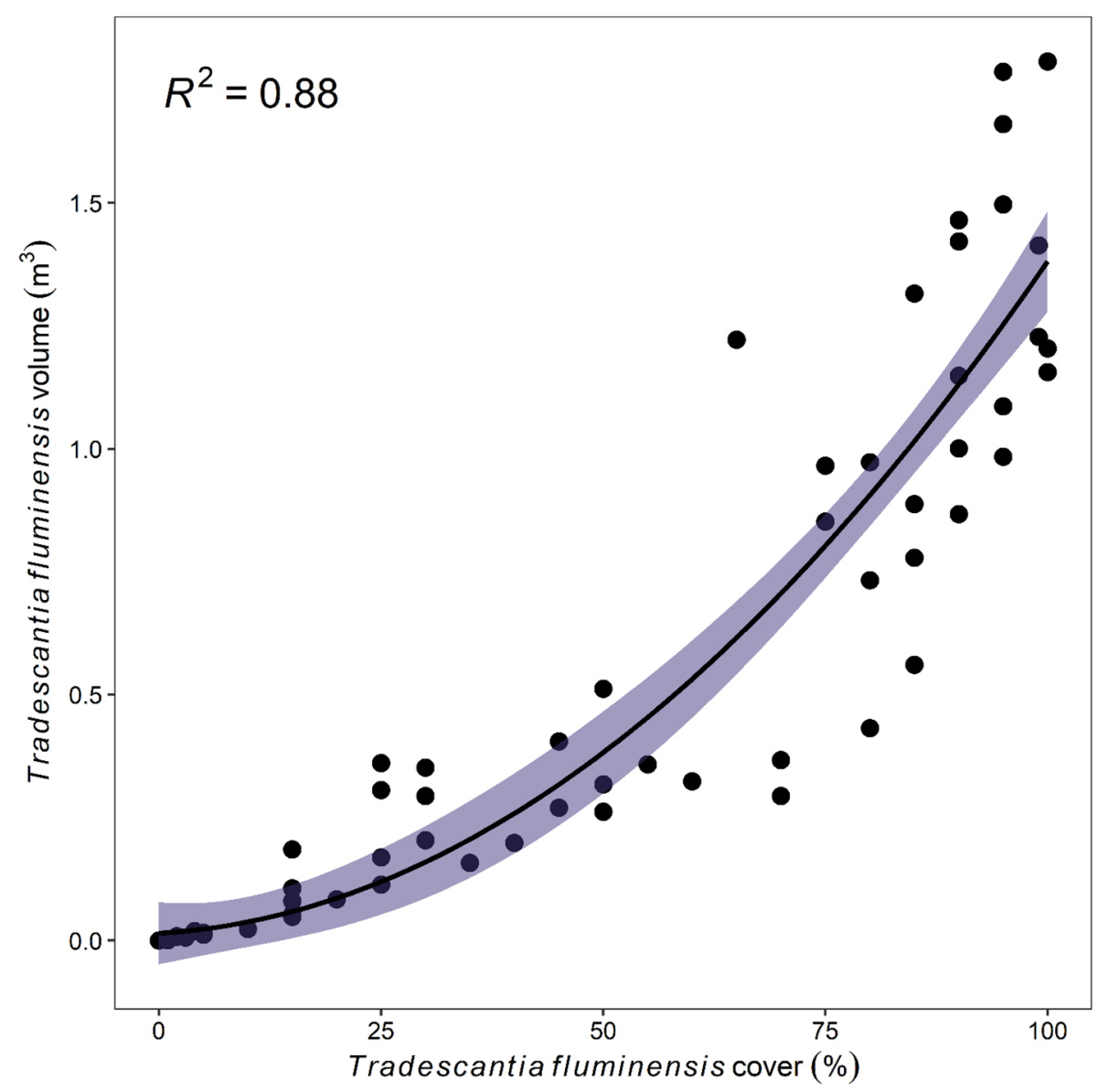

Figure 2. Relationship between Tradescantia fluminensis foliage cover (\%) and volume $\left(\mathrm{m}^{3}\right)$, measured in $2 \mathrm{~m} \times 2 \mathrm{~m}$ quadrats. The solid line represents the fitted values from a polynomial regression $(n=83)$.

as $\sim 70 \%$ for Delairea ordorata ${ }^{33}, 75-80 \%$ for Lantana camara ${ }^{12}$ and $\sim 80 \%$ for Baccharis halimifolia ${ }^{17}$. The $20 \%$ cover threshold we identified is also significantly different from the abundance-impact relationships previously determined for T. fluminensis by McAlpine et al. ${ }^{27}$ and Standish et al. ${ }^{34}$. First, our threshold was much lower than the $\sim 70$ to $80 \%$ volume threshold estimated by McAlpine et al. ${ }^{27}$. This difference potentially reflects greater resistance of the native plant community to the impacts of T. fluminensis in their New Zealand study system. Conversely, Standish et al. ${ }^{34}$ did not identify any impact threshold in native species richness or seedling density, both of which decreased exponentially with increasing T. fluminensis biomass.

We found that $T$. fluminensis cover and volume scaled positively but non-linearly, since infestations tended to rapidly get deeper with increasing cover. This resulted in no identifiable threshold when considering T. fluminensis volume, with native richness, abundance and diversity all decreasing by around $50 \%$ from 0 to 0.75 $\mathrm{m}^{3}$. Indeed, we detected negative exponential declines in native species indicators with increasing T. fluminensis volume. In contrast, McAlpine et al..$^{27}$ found a volume impact threshold of around $0.75-1.00 \mathrm{~m}^{3}$ of $T$. fluminensis, below which native species richness and abundance did not decline. Our results highlight that invasion abundance-impacts accumulate differently over a gradient of invasion depending on which metric of invader abundance (in our cases, cover versus volume) is modelled.

Non-native plant impact thresholds on native vegetation do not vary across gradients of anthropogenic landscape modification. Landscape context had limited influence on the abundanceimpact relationships between T. fluminensis and native species richness, abundance, and diversity. Although all landscape factors we measured featured in supported models at least once, most had no significant effect on native response variables. Distance to stream, footpath and forest edge were the most common factors that contributed to explaining some variation in the native plant metrics, without themselves having significant main or interactive effects with $T$. fluminensis invasion. The one exception was the relationship between $T$. fluminensis volume and native diversity. We found that the magnitude of reduction in native diversity in response to $T$. fluminensis invasion (based on invader volume) increased with distance from a stream or footpath. The specific mechanisms underpinning this interactive effect are unclear. Stream embankments infested with shallow-rooted T. fluminensis plants are regularly disturbed by floodwater, which can rapidly dislodge large T. fluminensis mats that raft downstream (Gooden Pers. Obs.), whilst native species, particularly those with deeper root networks, 


\begin{tabular}{|c|c|c|c|c|c|}
\hline \multirow[b]{2}{*}{ Native growth form } & \multirow[b]{2}{*}{ Effect } & \multicolumn{2}{|l|}{ Species richness } & \multicolumn{2}{|l|}{ Relative abundance } \\
\hline & & Coefficient $(95 \% \mathrm{CI})$ & $\mathrm{Z}$ & Coefficient $(95 \% \mathrm{CI})$ & $\mathrm{Z}$ \\
\hline \multirow{7}{*}{ Climbers } & Intercept & $-2.07(-3.51,-0.63)$ & 2.81 & $-1.52(-2.17,-0.87)$ & 4.56 \\
\hline & Trad (linear) & $-19.34(-36.94,-1.72)$ & 2.15 & $-1.29(-2.02,-0.56)$ & 3.45 \\
\hline & Trad (quad.) & $-5.21(-13.16,2.73)$ & 1.29 & & \\
\hline & Dist. to forest edge & $0.03(-0.08,0.38)$ & 0.35 & $0.02(-0.10,0.37)$ & 0.32 \\
\hline & Dist. to garden & $0.06(-0.11,0.52)$ & 0.48 & $0.06(-0.10,0.50)$ & 0.49 \\
\hline & Dist. to road & $0.06(-0.64,0.19)$ & 0.42 & $-0.04(-0.55,0.21)$ & 0.35 \\
\hline & Dist. to footpath & $0.01(-0.27,0.46)$ & 0.15 & $0.01(-0.21,0.42)$ & 0.20 \\
\hline \multirow{7}{*}{ Graminoids } & Intercept & $-0.24(-0.51,0.02)$ & 1.80 & $0.84(0.58,1.09)$ & 6.33 \\
\hline & Trad (linear) & $-0.53(-0.83,-0.24)$ & -3.57 & $-9.10(-11.73,-6.47)$ & 6.78 \\
\hline & Trad (quad.) & & & $-1.92(-4.00,0.17)$ & 1.80 \\
\hline & Dist. to footpath & $0.03(-0.10,0.32)$ & 0.43 & $0.06(-0.06,0.33)$ & 0.60 \\
\hline & Dist. to forest edge & $-0.01(-0.28,0.17)$ & 0.19 & & \\
\hline & Dist. to stream & & & $0.36(0.14,0.58)$ & 3.27 \\
\hline & Trad $\times$ stream & & & $0.34(0.12,0.56)$ & 3.03 \\
\hline \multirow{10}{*}{ Ground ferns } & Intercept & $0.23(0.02,0.42)$ & 2.28 & $1.69(1.56,1.82)$ & 25.04 \\
\hline & Trad (linear) & $-0.39(-0.61,-0.18)$ & -3.53 & $-4.95(-6.42,-3.48)$ & 6.62 \\
\hline & Trad (quad.) & & & $-1.09(-2.08,-0.12)$ & 2.18 \\
\hline & Dist. to garden & & & $-0.16(-0.35,0.02)$ & 1.69 \\
\hline & Dist. to stream & & & $-0.05(-0.01,0.16)$ & 0.92 \\
\hline & Dist. to footpath & & & $-0.01(-0.16,0.10)$ & 0.22 \\
\hline & Dist. to road & & & $-0.06(-0.05,-0.15)$ & 0.28 \\
\hline & Trad $\times$ garden & & & $-0.07(-0.44,0.38)$ & 0.56 \\
\hline & Trad $\times$ footpath & & & $-0.03(-0.32,0.01)$ & 0.43 \\
\hline & Trad $\times$ stream & & & $-0.01(-0.19,0.06)$ & 0.22 \\
\hline \multirow{10}{*}{ Tree ferns } & Intercept & $-0.74(-1.24,-0.23)$ & 2.87 & $-0.79(-1.70,0.12)$ & 1.70 \\
\hline & Trad (linear) & $-0.59(-1.16,-0.02)$ & 2.03 & $-13.50(-22.2,-4.8)$ & 3.03 \\
\hline & Trad (quad.) & & & $-3.64(-7.91,-0.63)$ & 1.67 \\
\hline & Dist. to garden & $-0.17(-1.71,0.16)$ & 0.43 & $-1.13(-2.40,0.07)$ & 1.74 \\
\hline & Dist. to stream & $-0.06(-0.51,0.15)$ & 0.46 & $-0.13(-0.71,0.11)$ & 0.66 \\
\hline & \begin{tabular}{|l|} 
Dist. to road \\
\end{tabular} & $-0.22(-1.01,0.21)$ & 0.71 & $-0.47(-1.14,-0.01)$ & 1.35 \\
\hline & Dist. to footpath & & & $-0.07(-0.75,0.21)$ & 0.42 \\
\hline & Dist. to forest edge & & & $0.01(0.40,0.79)$ & 0.15 \\
\hline & Trad $\times$ road & $-0.06(-1.35,0.47)$ & 0.27 & & \\
\hline & Trad $\times$ garden & $-0.19(-1.88,0.17)$ & 0.44 & $-1.75(-3.17,-0.44)$ & 2.34 \\
\hline \multirow{6}{*}{ Spreading herbs } & Intercept & $-0.40(-0.70,-0.10)$ & 2.59 & $0.45(0.11,0.79)$ & 2.64 \\
\hline & Trad (linear) & $-0.75(-1.09,-0.41)$ & 4.31 & $-10.00(-13.29,-6.71)$ & 5.95 \\
\hline & Trad (quad.) & & & $-2.85(-5.49,-0.20)$ & 2.11 \\
\hline & Dist. to footpath & $-0.02(-0.38,0.15)$ & 0.31 & $-0.05(-0.44,0.10)$ & 0.46 \\
\hline & Dist. to forest edge & $-0.01(-0.31,0.15)$ & 0.25 & $-0.01(-0.30,0.17)$ & 0.19 \\
\hline & Dist. to garden & $-0.01(-0.29,0.18)$ & 0.18 & $-0.02(-0.35,0.13)$ & 0.29 \\
\hline \multirow{10}{*}{ Tufted herbs } & Intercept & $-0.29(-0.60,0.02)$ & 1.86 & $0.01(-0.53,0.56)$ & 0.04 \\
\hline & Trad (linear) & $-0.11(-3.26,3.05)$ & 0.07 & $-0.72(-5.21,-3.78)$ & 0.31 \\
\hline & Trad (quad.) & $-2.68(-5.26,-0.10)$ & 2.04 & $-5.17(-9.03,-1.32)$ & 2.63 \\
\hline & Dist. to road & $0.28(0.01,0.56)$ & 2.04 & $0.46(0.04,0.88)$ & 2.16 \\
\hline & Dist. to garden & $0.23(-0.09,0.55)$ & 1.42 & $0.16(-0.20,1.06)$ & 0.56 \\
\hline & Dist. to stream & $-0.03(-0.45,0.18)$ & 0.30 & $-0.17(-0.79,0.14)$ & 0.72 \\
\hline & Dist. to footpath & $-0.01(-0.15,0.29)$ & 0.23 & & \\
\hline & Dist. to forest edge & & & $-0.17(-1.24,0.24)$ & 0.53 \\
\hline & Trad $\times$ garden & $0.36(-0.08,0.80)$ & 1.61 & $0.09(-0.16,-1.37)$ & 0.35 \\
\hline & Trad $\times$ road & $0.02(-0.29,0.51)$ & 0.19 & & \\
\hline
\end{tabular}




\begin{tabular}{|c|c|c|c|c|c|}
\hline \multirow[b]{2}{*}{ Native growth form } & \multirow[b]{2}{*}{ Effect } & \multicolumn{2}{|l|}{ Species richness } & \multicolumn{2}{|l|}{ Relative abundance } \\
\hline & & Coefficient $(\mathbf{9 5} \% \mathrm{CI})$ & $\mathrm{Z}$ & Coefficient $(95 \% \mathrm{CI})$ & $\mathrm{Z}$ \\
\hline \multirow{9}{*}{ Shrubs } & Intercept & $-0.53(-0.89,-0.18)$ & 2.97 & $-0.19(-0.63,0.24)$ & 0.89 \\
\hline & Trad (linear) & $-7.75(-11.81,-3.69)$ & 3.74 & $-10.58(-14.98,-6.18)$ & 4.71 \\
\hline & Trad (quad.) & $-2.27(-5.11,0.56)$ & 1.57 & $-3.18(-6.52,0.15)$ & 1.87 \\
\hline & Dist. to road & $0.04(-0.09,0.35)$ & 0.46 & $0.24(-0.07,0.66)$ & 0.23 \\
\hline & Dist. to footpath & $-0.02(-0.38,0.15)$ & 0.28 & & \\
\hline & Dist. to stream & $-0.01(-0.32,0.19)$ & 0.17 & $-0.04(-0.52,0.16)$ & 0.72 \\
\hline & Dist. to garden & $-0.02(-0.47,0.12)$ & 0.28 & $-0.09(-0.59,0.09)$ & 0.57 \\
\hline & Dist. to forest edge & & & $-0.01(-0.41,0.21)$ & 0.88 \\
\hline & $\operatorname{Trad} \times$ road & & & $0.02(-0.43,0.74)$ & 0.86 \\
\hline \multirow{8}{*}{ Trees } & Intercept & $-0.44(-0.84,-0.04)$ & 2.18 & $-0.33(-1.03,0.37)$ & 0.90 \\
\hline & Trad (linear) & $-0.32(-0.74,0.16)$ & 1.29 & $-0.47(-1.22,0.24)$ & 0.19 \\
\hline & Dist. to road & $-0.38(-0.97,0.09)$ & 1.32 & $-0.59(-1.32,0.04)$ & 0.12 \\
\hline & Dist. to forest edge & $0.33(-0.49,1.85)$ & 0.62 & $0.57(-0.65,2.53)$ & 0.47 \\
\hline & Dist. to garden & $0.01(-0.17,0.40)$ & 0.23 & $-0.09(-1.35,0.43)$ & 0.74 \\
\hline & Dist. to stream & & & $0.01(-0.29,0.55)$ & 0.88 \\
\hline & Trad $\times$ forest edge & $0.28(-0.13,1.96)$ & 0.54 & $0.34(-0.38,2.68)$ & 0.62 \\
\hline & Trad $\times$ road & $-0.03(-1.09,0.39)$ & 0.22 & & \\
\hline
\end{tabular}

Table 2. Model results testing the effects of Tradescantia fluminensis foliage cover (\%), volume $\left(\mathrm{m}^{3}\right)$ and landscape predictor variables on native species richness and relative $\%$ foliage cover abundance of native plant growth forms; $n=83$. Standardised regression coefficients with $95 \%$ confidence intervals and test statistic (GLMM Z-value for species richness and relative abundance, LMM $\mathrm{t}$-value for diversity) from model averaging are shown for predictor variables that featured in the top-ranked models $(\Delta \mathrm{AICc}<2)$ for each native response variable (see Table S2). Bold values denote significant effects $(P<0.05)$.

may be either relatively less disturbed by flooding or can rapidly revegetate denuded soil. We suggest that the proximity to streams, and commensurate disturbance by floodwater, may possibly ameliorate (but not completely offset or reverse) the adverse effects of dense T. fluminensis infestations on native diversity.

Despite other studies finding strong evidence that invader impacts are amplified where disturbance is higher ${ }^{24,25,35}$, we did not observe more severe impacts of $T$. fluminensis on native species when closer to roads or the forest-urban interface. This may result from the surveys being undertaken in a highly human-modified landscape, with remnant native forests restricted in many cases to linear strips along stream embankments within a suburban-agricultural matrix. Consequently, the pool of resident native species may already have been significantly reduced across the landscape prior to T. fluminensis invasion, thus resulting in the null effect of contemporary landscape variables on most native vegetation diversity. Nevertheless, our results show that the strongest current driver of local vegetation diversity, independent of landscape context, is proliferation of a non-native plant invader.

Comparing abundance-impact relationships: whole community versus growth form metrics. A major aim of this study was to determine the abundance-impact relationships between T. fluminensis and native species growth forms. Overall, there was discordance between the abundance-impact relationships apparent for whole community metrics and those for plant growth forms. When T. fluminensis abundance was assessed as percentage foliar cover, impact thresholds were observed for all three community metrics. For growth forms, however, impact thresholds in species richness were detectable only for climbers and shrubs. In terms of relative abundance, a threshold abundance-impact relationship was detectable for shrubs and spreading herbs, but no longer for climbers. These results could reflect differences in native species' responses to non-native plant invasion arising from their intrinsic functional traits and highlight the importance of considering contextspecific patterns of community change when quantifying the impacts of non-native plant invasion on recipient ecosystems (see related discussion in ${ }^{36,37}$ ). Alternatively, they could be an artefact of the low representation of species from each growth form in individual plots, such that invader abundance-impact thresholds become apparent when the data for all growth forms are aggregated at the community level.

Maximum species richness and relative abundance of tufted herbs at moderate cover of T. fluminensis (40-50\% cover; Fig. 3) were unexpected results. This pattern suggests that tufted herbs may be naturally outcompeted by other native species in this community and initially benefit from $T$. fluminensis invasion before decreasing again as invader cover increases beyond $50 \%$. The positive association with invasion could be due to either the decreased abundance of competitively dominant natives, the altered structural and abiotic conditions created by invasion (e.g. lower light ${ }^{34}$ ), or a coincidental response or tufted herbs to the same environmental conditions that promote T. fluminensis invasion. While there are some examples of native plants benefiting from invasive plants (e.g. ${ }^{38}$ ) and positive ecological effects more generally from invasion (e.g. ${ }^{39}$ ), a humped abundance-impact relationship is rarely hypothesised (i.e. not presented as a potential relationship in Bradley et al. ${ }^{10}$ ) and is rarely empirically demonstrated. The lack of discussion around "intermediate invasion" is interesting given that the 

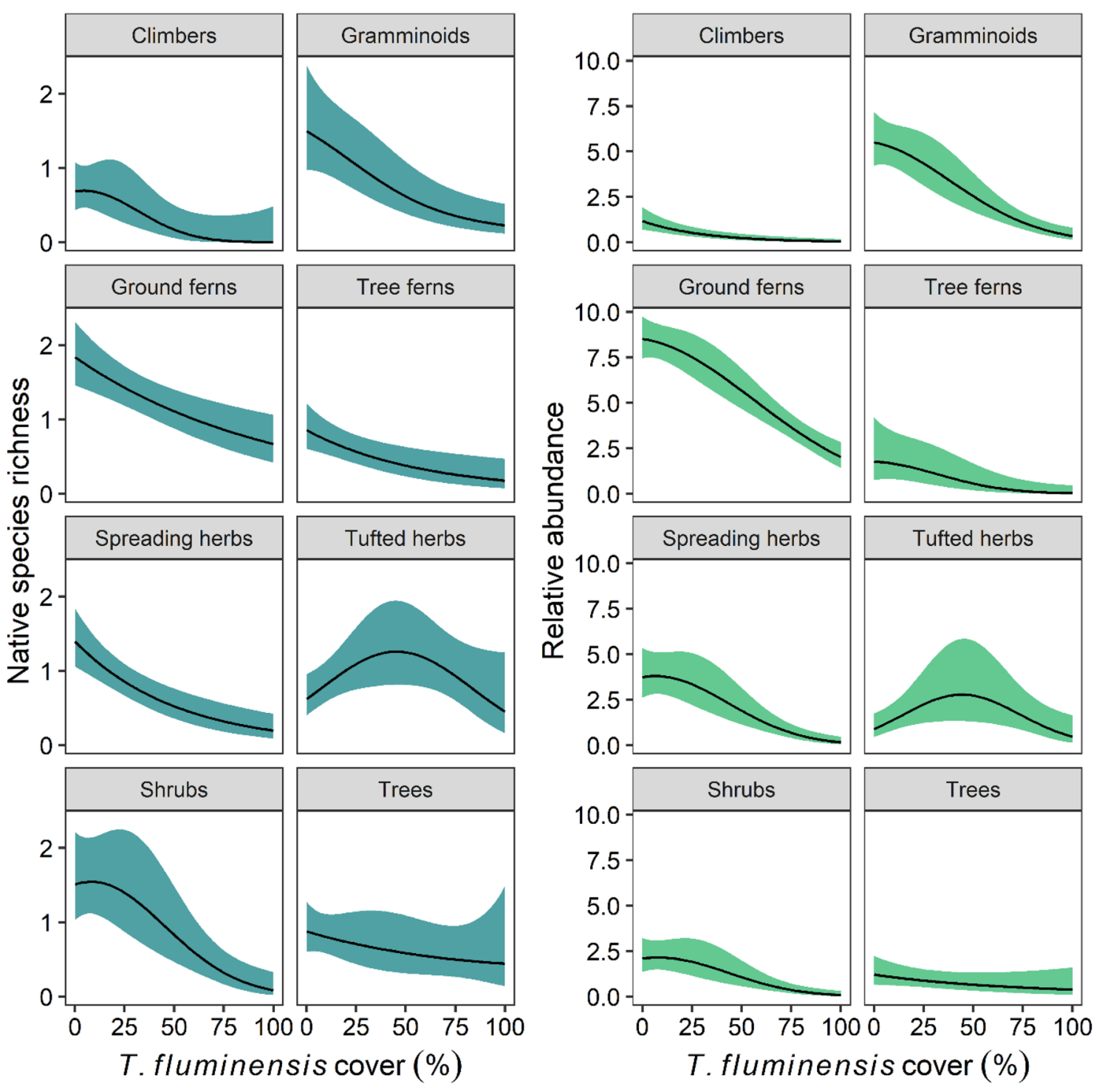

Figure 3. The response of native species richness and relative $\%$ foliage cover abundance of different plant functional growth forms to increasing \% foliage cover of Tradescantia fluminensis, measured in $2 \mathrm{~m} \times 2 \mathrm{~m}$ quadrats $(n=83)$. Solid black lines represent predicted values from the top-ranked GLMM, bound by $95 \%$ confidence intervals. These predictions are based on averaged predicted values from all top-ranked model $(\triangle \mathrm{AICc}<2)$, with other predictor variables held at their mean values.

humped-back diversity-productivity ${ }^{40}$ and diversity-disturbance ${ }^{41}$ relationships are important foundation theories of community ecology.

Conclusions and management implications. The form of the abundance-impact relationship has important implications for the management of an invasive plant species ${ }^{11,14,15,42}$. Where the abundance-impact relationship is non-linear and an impact threshold can be identified, the appropriate management goal would be to maintain invader abundance below it (so-called "maintenance control"11). However, we have shown that for some growth forms the abundance-impact relationship for T. fluminensis is either exponential or linear, meaning that these plants are negatively impacted at low invasive plant cover values. To conserve these species, the "action threshold" (i.e., the target abundance of the invader at which management intervention is triggered) for the control of T. fluminensis would likely be lower than the impact threshold assessed in terms of less sensitive community metrics, such as native species richness, relative abundance, and diversity.

Herbicide application is considered the only practical way to control large infestations of T. fluminensis ${ }^{43}$. However, in Australia some of the herbicides registered for its control cannot be used close to waterways. Smaller infestations can be hand pulled, raked and rolled-up for manual removal, but plants will regrow from any remaining stem or stem fragments, meaning that control of this species is currently a protracted and labour-intensive activity. Biological control is an emerging management option that could potentially provide effective, sustainable control of T. fluminensis in Australia ${ }^{44,45}$. Given the community resistance to low-density invasion we observed, 
indications are that the recent introduction of a fungal biological control agent (Kordyana brasiliensis) could be highly beneficial to the native plant community should it prove effective at maintaining T. fluminensis at low cover levels.

With a well-established, widespread invader, such as T. fluminensis, a range of invasion statuses will exist in invasible plant communities, from uninvaded sites to those that are heavily invaded, with depauperate native diversity. In the context of scant available resources for active management intervention, there would presumably be required some a priori triaging of sites by some index of conservation value to decide where to maintain $T$. fluminensis cover at low levels. This would allow practitioners to aim for near-complete removal (and ongoing suppression of invasion) of T. fluminensis in areas identified as high conservation value, such as stands of cool temperate rainforest that contain threatened species. Further research is required to determine the prevalence of invasive plant impact thresholds and, where such abundance-impact relationships exist, to resolve the issue of whether to manage invasive plants according to community impact metrics or according to impacts of the invader on the community's least resistant growth form(s).

\section{Materials and methods}

Authors declare that this manuscript complies with all the institutional, national, and international guidelines and legislation, regarding all species and habitats studied.

Study system. Tradescantia fluminensis Vell. (family Commelinaceae, commonly known as small-leaf spiderwort) is a sprawling herb native to rainforests of south-eastern Brazil ${ }^{43}$. Adventitious roots forming along stem nodes enable rapid clonal spread, including from fragmented stems ${ }^{43}$. Tradescantia fluminensis is considered a significant invasive plant of subtropical to cool temperate rainforest ecosystems worldwide, especially in New Zealand and Australia ${ }^{46}$, where it was introduced as a popular ornamental house and garden plant ${ }^{43}$. Naturalisation in native forests likely resulted from clonal propagation from adjacent suburban gardens, as well as from illegal dumping of garden waste ${ }^{47}$. In New Zealand, T. fluminensis can reduce the abundance and richness of native vegetation ${ }^{27,34}$, disrupt ecosystem processes, such as leaf litter decomposition rates and soil nutrients ${ }^{48}$, and native faunal assemblages (e.g. invertebrates ${ }^{48,49}$ ). Effects of T. fluminensis on Australian forest ecosystems are poorly understood.

Our study investigated the effects of $T$. fluminensis invasion on native plant community composition in the Dandenong Ranges, approximately $40 \mathrm{~km}$ east of Melbourne (Victoria), Australia (map provided in Appendix 1). The Dandenong Ranges has a moist temperate climate with mean annual rainfall of $\sim 1,000 \mathrm{~mm}$ (Monbulk weather station ${ }^{50}$ ) and mean minimum and maximum daytime temperatures of $9.8^{\circ} \mathrm{C}$ (austral winter, July) and $24.5^{\circ} \mathrm{C}$ (austral summer, January), respectively (Ferny Creek weather station, Bureau of Meteorology 2020).

Plant communities across the Dandenong Ranges are characterised by a mix of tall wet eucalypt forests (dominated by Eucalyptus regnans, E. obliqua and E. cypellocarpa, with a dense understorey of mesophyllous rainforest trees, shrubs, herbs and ferns) and cool temperate rainforests (characterised by Acacia melanoxylon, Atherosperma moschatum and the tree ferns Cyathea spp. and Dicksonia australis), located along streamlines in moist gullies ${ }^{51}$. Except for several large reserves located within the Dandenong Ranges National Park (e.g. Ferntree Gully and Sherbrooke Forest; Incoll et al. ${ }^{52}$ ), remnant cool temperate rainforest occurs in fragmented, often linear patches along streams and roadside reserves intermixed with anthropogenic landscape features, such as suburban dwellings, footpaths, roads, industrial infrastructure and cleared pastures used for cultivation of crops or livestock grazing. Recent surveys by Incoll et al. ${ }^{52}$ identified T. fluminensis as a high-priority invasive plant for management across the Dandenong Ranges, due to its widespread distribution and ability to invade deeply shaded, cool temperate rainforest habitats without primary disturbance, where it can dominate the understorey vegetation and suppress the growth of native flora (see example photographs of $T$. fluminensis infestations in Appendix 2).

Survey design and vegetation sampling. To assess the interactive effects of variation in T. fluminensis abundance and landscape context, our monitoring plots needed to be stratified in two ways. First, plots needed to represent the full gradient of invader abundance (0-100\% cover) relatively evenly (i.e. approximately equal representation of no, low, medium, and high cover plots). Second, that gradient of invasion needed to be replicated relatively evenly among different landscape contexts, from highly modified to largely intact remnant vegetation. This stratification was achieved by targeted plot selection in the field. Across the study landscape (Appendix 1), eight different areas of streamside native cool temperate rainforest remnants were selected. Six of these areas were highly variable in their landscape context, with part of the stream being close to industrial or high-density urbanisation, some parts being close to parks or other semi-natural lands, and other parts being close to other remnant vegetation (wet sclerophyll forest) (Table 3; Appendix 1). The other two areas were selected because they were comparatively less modified and represented the best examples of undisturbed remnant vegetation (Table 3). Within each area, plots were selected at locations of no (0\%), low ( 1 to 33\%), moderate ( 34 to $66 \%)$, and high $(\sim 67$ to $100 \%)$ T. fluminensis foliage cover within different landscape contexts. For example, if one part of a remnant area was near to a road and urban activity, and a separate part was close to a cultivated paddock, then we would aim to establish plots representing the complete gradient of $T$. fluminensis cover in each of those two different parts. This targeted plot selection ensured a relatively even representation of invasion level within different qualitative assessments of landscape context. The level of replication within each area varied based on the size of the area and status of T. fluminensis, but the total replication among plots of no, low and high T. fluminensis cover was close to even (Table 3 ).

A total of 83 monitoring plots $(2 \times 2 \mathrm{~m})$ was established across our study landscape following this targeted selection approach. This plot size has been shown previously to be a suitable scale to assess the responses of 


\begin{tabular}{|l|c|l|l|l|l|}
\hline \multirow{2}{*}{ Landscape area } & \multicolumn{5}{l}{ Tradescantia fluminensis foliage cover (\%) } \\
\cline { 2 - 6 } & Absent (0) & Low ( 1 to 33) & Mod. ( 34 to 66) & High ( 67 to 100) \\
\hline Variable landscape context & 1 & 0 & 1 & 3 \\
\hline Emerald Creek & 0 & 2 & 1 & 3 \\
\hline Monbulk Creek-Birdsland & 1 & 4 & 2 & 3 \\
\hline Monbulk Creek-National Road & 12 & 7 & 1 & 15 \\
\hline Sassafras Creek & 3 & 0 & 0 & 0 \\
\hline Sherbrooke Forest-East & 0 & 1 & 1 & 1 \\
\hline Sayers Road & \multicolumn{5}{|l|}{} \\
\hline Low modification landscape context & 5 & 1 & 1 \\
\hline Clematis Creek-Monbulk Road & 9 & 3 & 2 & 0 \\
\hline Kokoda Memorial Walk & 0 & 22 & 9 & 26 \\
\hline Total & 26 & & \\
\hline
\end{tabular}

Table 3. Total number of sites representing varying levels of Tradescantia fluminensis foliage cover (\%) as identified across the eight different landscape areas.

\begin{tabular}{|c|c|c|c|}
\hline Variable & Description & Range & Type \\
\hline \multicolumn{4}{|l|}{ Fixed effects } \\
\hline Trad cover $(\%)$ & Visually estimated cover of live T. fluminensis per plot & $0-100($ median $=25)$ & Integer \\
\hline Trad volume $\left(\mathrm{m}^{3}\right)$ & Average standing height multiplied by foliage cover of $T$. fluminensis & $0-1.79($ median $=0.17)$ & Numerical \\
\hline Distance to forest edge $(\mathrm{m})$ & Minimum linear distance to an edge of the forest remnant (measured remotely) & $2-803($ median $=50)$ & Integer \\
\hline Distance to stream (m) & $\begin{array}{l}\text { Minimum linear distance to a stream, a potential source of } T \text {. fluminensis propagules } \\
\text { (measured in the field) }\end{array}$ & $0-82($ median $=5)$ & Integer \\
\hline Distance to road $(\mathrm{m})$ & $\begin{array}{l}\text { Minimum linear distance to a road, an indicator of relative proximity to urban distur- } \\
\text { bance (measured remotely) }\end{array}$ & $5-821($ median $=50)$ & Integer \\
\hline Distance to footpath (m) & $\begin{array}{l}\text { Minimum linear distance to a pedestrian footpath, an indicator of relative proximity to } \\
\text { urban disturbance (measured remotely) }\end{array}$ & $1-222($ median $=17)$ & Integer \\
\hline Distance to garden (m) & $\begin{array}{l}\text { Minimum linear distance to a road, an indicator of relative proximity to urban distur- } \\
\text { bance and potential source of } T \text {. fluminensis propagules (measured remotely) }\end{array}$ & $5-951($ median $=86)$ & Integer \\
\hline \multicolumn{4}{|l|}{ Random effects } \\
\hline "Area": to account for spatial autocorrelation & $\begin{array}{l}\text { Landscape area identifier that represents the spatial clustering of plots along different } \\
\text { streams (see Table 1) }\end{array}$ & - & Factor (8 levels) \\
\hline
\end{tabular}

Table 4. Explanatory variables used in the analysis.

diverse ground-layer forest vegetation to invasion by herbaceous non-native scramblers (e.g. T. fluminensis) in New Zealand ${ }^{27}$ and grasses (e.g. the stoloniferous grass Stenotaphrum secundatum) in Australia ${ }^{53}$. In each 4 $\mathrm{m}^{2}$ plot, we visually estimated T. fluminensis percentage foliage cover to the nearest $5 \%$. We also calculated the volume $\left(\mathrm{m}^{3}\right)$ of space within the ground-layer vegetation occupied by T. fluminensis by multiplying average standing height (m; calculated from 10 random points across the plot as per Standish et al. ${ }^{34}$ ) by planar foliage cover (converted from \% to $\mathrm{m}^{2}$ ), as a surrogate measure of biomass. Indeed, Standish et al. ${ }^{34}$ found that this measure of T. fluminensis volume was a very strong positive predictor of biomass $\left(\mathrm{g} . \mathrm{m}^{-2}\right)$. While plots were initially selected based on a quick categorical identification of T. fluminensis cover, we quantified cover and volume in this way so "invasion" could be considered a continuous variable in our analyses (Table 4).

We recorded the identity and origin (native or non-native) of all resident plant species rooted within and overhanging each $4 \mathrm{~m}^{2}$ plot. We only sampled vegetation growing within the ground and shrub layers (to a height of $\leq 2 \mathrm{~m}$ ), which is likely to interact directly and most strongly with $T$. fluminensis, compared with mature, long-lived woody vegetation in the upper canopy layers. We nevertheless sampled the seedlings and saplings of shrubs and trees that were $>2 \mathrm{~m}$ tall at maturity if present within the ground-layer vegetation, as a measure of impacts of T. fluminensis invasion on forest recruitment. Non-native species were defined as those introduced to the Dandenong Ranges region of Victoria from other countries or other parts of Australia ${ }^{54}$.

Species abundance was quantified using a modified Braun-Blanquet scale of percentage foliage cover: $1,<5 \%$ and a single individual; $2,<5 \%$ and a few individuals; $3,<5 \%$ with many individuals but uncommon across the plot; $4,<5 \%$ and common across the plot; $5,<5 \%$ and very abundant across the plot; $6,5-20 \% ; 7,21-40 \% ; 8$, $41-60 \% ; 9,61-80 \% ; 10,81-100 \%^{12}$. Species were assigned to one of six growth form categories: (1) climbers (combining herbaceous twiners, scramblers and woody vines); (2) graminoids (combining grasses, sedges and rushes); (3) herbs, subdivided into tufted and spreading (i.e. rhizomatous and stoloniferous) forms; (4) ferns, subdivided into tree ferns (e.g. Cyathea spp. and Dicksonia australis) and ground-layer forms; (5) shrubs; (6) trees.

We derived information about five landscape-scale variables associated with anthropogenic development, using a combination of field measurements and spatial analysis on Google Earth (https://earth.google.com/web), 
adapted from procedures developed by Maisy et al. ${ }^{51}$. For each of the 83 plots, using the Ruler (Line) function in Google Earth, we calculated the minimum linear distance $(\mathrm{m})$ from the nearest suburban garden (shown to be an important predictor of T. fluminensis invasion, including by dumping of garden waste ${ }^{47,55}$ ), footpath, road and forest edge (defined as the interface between the remnant native canopy and an anthropogenic landscape feature, which in many cases was a road or cluster of residential dwellings). Distance ( $m)$ to the water's edge of the nearest stream was quantified in the field using a tape measure. While plots were initially selected based on a qualitative assessment of landscape context, we quantified these five landscape properties on a continuous scale to both objectively represent landscape context and explicitly test whether these contextual factors were influential (Table 4).

Data analysis. All analyses were performed using R version 3.6.0 $0^{56}$.

We fitted generalised linear mixed models to native species richness (number of native species per $4 \mathrm{~m}^{2} \mathrm{plot}$ ) and relative abundance (sum of $\%$ foliage cover abundance scores per plot) with Poisson error distributions and log-link functions. We fitted linear mixed models to native species diversity (Shannon-Weiner Diversity Index), as the data were normally distributed. We checked for multicollinearity amongst predictor variables and determined that $T$. fluminensis cover and volume were strongly correlated $(r=0.88$, Fig. 1$)$. Therefore, two separate models were used to test these effects on each response variable (referred to hereafter as the "trad cover model" and "trad volume model"). Importantly, no correlations were observed between variables representing "invasion" and those representing "landscape context", meaning our targeted plot selection achieved its aim of a stratified design that could test the interactive effects of these two factors. Each native plant response variable was modelled as a function of both trad cover and volume, distance to forest edge, distance to stream, distance to road, distance to footpath, distance to garden, and the interaction of trad with each of the five distance measures (full model). All predictor variables were scaled to a mean of zero and a standard deviation of one prior to modelling to allow direct comparison of regression coefficients. We used Akaike's Information Criterion corrected for small sample sizes (AICc) to rank subsets of the full model and determine the best (lowest AICc) and supported $(\triangle \mathrm{AICc}<2)$ models. We further sought to improve explanatory power by examining whether modelling trad (cover or volume) as a polynomial factor in supported models decreased AICc, in order to detect impact threshold effects (as per ${ }^{12}$ ).

Plots of residuals against fitted values, residual frequency histograms, quantile-quantile plots and residual variation box plots were examined to verify homogeneity and expected properties of residuals. Tests for overdispersion were undertaken to assess whether there was additional variance in the data than assumed by the error distributions. If models were overdispersed, as was the case for relative native abundance in both models, a random observation was included as a random effect to correct for the unexplained variance ${ }^{57}$. We used mixed models to account for spatial autocorrelation of plots with the inclusion of the landscape-level random effect "cluster" in all models. Model coefficients and 95\% confident intervals were averaged and the predicted values calculated across the set of supported models (full averaging). Model predictions were the averaged predicted values calculated for each supported model, not a single prediction from the average coefficient. Any non-linear response curves were visually inspected for clear points of change in slope as indicators of impact thresholds.

Models were fitted using the 'glmer' function in the "lme4" package. Subsets of the full model were ranked using the 'dredge' function and coefficients averaged from supported models using the 'model.avg' function in the "MuMIn" package. Confidence intervals for averaged coefficients were estimated using the 'confint' function in the "stats" package, and predicted values were calculated using the 'predictSE' function in the "AICcmodavg" package.

We also fitted generalised linear mixed models to the native species richness and relative abundance of each of eight functional growth forms (climber, graminoids, ground ferns, tree ferns, spreading herbs, tufted herbs, shrubs, and trees). Model design (fixed and random effects), selection, averaging and checking follow as described above. Only "trad cover models" were utilised to test the main effects of T. fluminensis invasion on native plant growth forms as we were more interested in identifying patterns along the gradient of invasion establishment (from low to high cover) than in quantifying invasion dominance (the exponential development of volume at high cover) (Fig. 2).

Consent for publication. All authors provide consent for publication.

\section{Data availability}

Data supporting our results is available as supplementary material, Appendix 3.

Received: 24 May 2021; Accepted: 6 September 2021

Published online: 15 October 2021

\section{References}

1. Vilà, M. et al. Ecological impacts of invasive alien plants: A meta-analysis of their effects on species, communities and ecosystems. Ecol. Lett. 14, 702-708 (2011).

2. Pyšek, P. et al. A global assessment of invasive plant impacts on resident species, communities and ecosystems: The interaction of impact measures, invading species' traits and environment. Glob. Chang. Biol. 18, 1725-1737 (2012).

3. Barney, J. N., Tekiela, D. R., Dollete, E. S. \& Tomasek, B. J. What is the "real" impact of invasive plant species?. Front. Ecol. Environ. 11, 322-329 (2013).

4. O’Loughlin, L. S., Gooden, B., Barney, J. N. \& Lindenmayer, D. B. Surrogacy in invasion research and management: Inferring “impact” from “invasiveness". Front. Ecol. Environ. 17, 464-473 (2019). 
5. Crystal-Ornelas, R. \& Lockwood, J. L. The 'known unknowns' of invasive species impact measurement. Biol. Invasions https://doi. org/10.1007/s10530-020-02200-0 (2020).

6. Foster, C. N. et al. How practitioners integrate decision triggers with existing metrics in conservation monitoring. J. Environ. Manage. 230, 94-101 (2019).

7. Hulme, P. E. Weed risk assessment: A way forward or a waste of time?. J. Appl. Ecol. 49, 10-19 (2012).

8. Meyerson, L. A., Simberloff, D., Boardman, L. \& Lockwood, J. L. Toward, "rules" for studying biological invasions. Bull. Ecol. Soc. Am. 100, 1689-1699 (2019).

9. Hulme, P. E. et al. Bias and error in understanding plant invasion impacts. Trends Ecol. Evol. 28, 212-218 (2013).

10. Bradley, B. A. et al. Disentangling the abundance-impact relationship for invasive species. Proc. Natl. Acad. Sci. USA 116, 99199924 (2019).

11. Panetta, F. D. \& Gooden, B. Managing for biodiversity: Impact and action thresholds for invasive plants in natural ecosystems. NeoBiota 34, 53-66 (2017).

12. Gooden, B., French, K., Turner, P. J. \& Downey, P. O. Impact threshold for an alien plant invader, Lantana camara L., on native plant communities. Biol. Conserv. 142, 2631-2641 (2009).

13. Bernard-Verdier, M. \& Hulme, P. E. Alien plants can be associated with a decrease in local and regional native richness even when at low abundance. J. Ecol. 107, 1343-1354 (2019).

14. Panetta, F. D., O'Loughlin, L. S. \& Gooden, B. Identifying thresholds and ceilings in plant community recovery for optimal management of widespread weeds. NeoBiota 42, 1-18 (2019).

15. Sofaer, H. R., Jarnevich, C. S. \& Pearse, I. S. The relationship between invader abundance and impact. Ecosphere 9 , e02415 (2018).

16. Gooden, B. \& French, K. Impacts of alien plant invasion on native plant communities are mediated by functional identity of resident species, not resource availability. Oikos 124, 298-306 (2015).

17. Fried, G. \& Panetta, F. D. Comparing an exotic shrub's impact with that of a native life form analogue: Baccharis halimifolia vs Tamarix gallica in Mediterranean salt marsh communities. J. Veg. Sci. 27, 812-823 (2016).

18. Chabrerie, O., Loinard, J., Perrin, S., Saguez, R. \& Decocq, G. Impact of Prunus serotina invasion on understory functional diversity in a European temperate forest. Biol. Invasions 12, 1891-1907 (2010).

19. O'Loughlin, L. S., Green, P. T. \& Morgan, J. W. The rise and fall of Leptospermum laevigatum: Plant community change associated with the invasion and senescence of a range-expanding native species. Appl. Veg. Sci. 18, 323-331 (2015).

20. Case, E. J., Harrison, S. \& Cornell, H. V. Do high-impact invaders have the strongest negative effects on abundant and functionally similar resident species?. Funct. Ecol. 30, 1447-1453 (2016).

21. González-Moreno, P., Diez, J. M., Ibáñez, I., Font, X. \& Vilà, M. Plant invasions are context-dependent: Multiscale effects of climate, human activity and habitat. Divers. Distrib. 20, 720-731 (2014).

22. Jauni, M., Gripenberg, S. \& Ramula, S. Non-native plant species benefit from disturbance: A meta-analysis. Oikos https://doi.org/ 10.1111/oik.01416 (2014).

23. Gill, R. A. et al. Niche opportunities for invasive annual plants in dryland ecosystems are controlled by disturbance, trophic interactions, and rainfall. Oecologia 187, 1-11 (2018).

24. Didham, R. K., Tylianakis, J. M., Gemmell, N. J., Rand, T. A. \& Ewers, R. M. Interactive effects of habitat modification and species invasion on native species decline. Trends Ecol. Evol. 22, 489-496 (2007).

25. Sokol, N. W., Kuebbing, S. E. \& Bradford, M. A. Impacts of an invasive plant are fundamentally altered by a co-occurring forest disturbance. Ecology 98, 2133-2144 (2017).

26. Iacarella, J. C., Mankiewicz, P. S. \& Ricciardi, A. Negative competitive effects of invasive plants change with time since invasion. Ecosphere 6, 1-14 (2015).

27. McAlpine, K. G., Lamoureaux, S. L. \& Westbrooke, I. Ecological impacts of ground cover weeds in New Zealand lowland forests. N. Z. J. Ecol. 39, 50-60 (2015).

28. MacDougall, A. S. \& Turkington, R. Are invasive species drivers or passengers of change in degraded ecosystems?. Ecology 86, $42-55$ (2005).

29. Didham, R. K., Tylianakis, J. M., Hutchison, M. A., Ewers, R. M. \& Gemmell, N. J. Are invasive species the drivers of ecological change?. Trends Ecol. Evol. 20, 470-474 (2005).

30. Kettenring, K. M. \& Adams, C. R. Lessons learned from invasive plant control experiments: A systematic review and meta-analysis. J. Appl. Ecol. 48, 970-979 (2011).

31. D’Antonio, C. \& Flory, S. L. Long-term dynamics and impacts of plant invasions. J. Ecol. 105, 1459-1461 (2017).

32. Prober, S. M., Thiele, K. R. \& Speijers, J. Competing drivers lead to non-linear native: Exotic relationships in endangered temperate grassy woodlands. Biol. Invasions 18, 3001-3014 (2016).

33. Alvarez, M. E. \& Cushman, J. H. Community-level consequences of a plant invasion: Effects on three habitats in Coastal California. Ecol. Appl. 12, 1434 (2002).

34. Standish, R. J., Robertson, A. W. \& Williams, P. A. The impact of an invasive weed Tradescantia fluminensis on native forest regeneration. J. Appl. Ecol. 38, 1253-1263 (2001).

35. Zeeman, B. J., McDonnell, M. J., Kendal, D. \& Morgan, J. W. Biotic homogenization in an increasingly urbanized temperate grassland ecosystem. J. Veg. Sci. 28, 550-561 (2017).

36. Hejda, M. Do species of invaded communities differ in their vulnerability to being eliminated by the dominant alien plants?. Biol. Invasions 15, 1989-1999 (2013).

37. Hejda, M., Štajerová, K., Pergl, J. \& Pyšek, P. Impacts of dominant plant species on trait composition of communities: Comparison between the native and invaded ranges. Ecosphere 10, 20 (2019).

38. Kuebbing, S. E. \& Nuñez, M. A. Negative, neutral, and positive interactions among nonnative plants: Patterns, processes, and management implications. Glob. Change Biol. 21, 926-934 (2015).

39. O'Loughlin, L. S. et al. Invasive shrub re-establishment following management has contrasting effects on biodiversity. Sci. Rep. 9, $4083(2019)$.

40. Grime, J. P. Competitive Exclusion in Herbaceous Vegetation. Nature 242, 344-347 (1973),

41. Connell, J. H. Diversity in tropical rain forests and coral reefs. Science 199, 1302-1310 (1978).

42. Barney, J. N., Smith, L. L. \& Tekiela, D. R. Weed risk assessments can be useful, but have limitations. Invasions Plant Sci. Manage. 9, 84-85 (2016).

43. Dugdale, T., McLaren, D. \& Conran, J. The biology of Australian weeds 65. 'Tradescantia fluminensis' Vell. Plant Prot. Q. 30, 116 (2015).

44. Fowler, S. V. et al. Tradescantia fluminensis, an exotic weed affecting native forest regeneration in New Zealand: Ecological surveys, safety tests and releases of four biocontrol agents from Brazil. Biol. Control 64, 323-329 (2013).

45. Morin L. Information package to support application to release the white smut-like fungus Kordyana brasiliensis for the biological control of wandering trad (Tradescantia fluminensis) in Australia. (CSIRO, Australia, 2017).

46. CABI. Tradescantia fluminensis (wandering Jew). In Invasive Species Compendium (2019).

47. Butcher, E. R. \& Kelly, D. Physical and anthropogenic factors predict distribution of the invasive weed Tradescantia fluminensis. Austral. Ecol. 36, 621-627 (2011).

48. Standish, R. J. et al. Invasion by a perennial herb increases decomposition rate and alters nutrient availability in warm temperate lowland forest remnants. Biol. Invasions. 6, 71-81 (2004). 
49. Toft, R. J., Harris, R. J. \& Williams, P. A. Impacts of the weed Tradescantia fluminensis on insect communities in fragmented forests in New Zealand. Biol. Conserv. 102, 31-46 (2001).

50. Bureau of Meteorology. Climate Data Online. http://www.bom.gov.au/climate/data/index.shtm (2020).

51. Maisey, A. C., Nimmo, D. G. \& Bennett, A. F. Habitat selection by the Superb Lyrebird (Menura novaehollandiae), an iconic ecosystem engineer in forests of south-eastern Australia. Austral. Ecol. 44, 503-513 (2019).

52. Incoll, B., Maisey, A. \& Adam, J. T. years of forest restoration in the Upwey Corridor, Dandenong Ranges, Victoria. Ecol. Manage. Restor. 19, 189-197 (2018).

53. Gooden, B. \& French, K. Non-interactive effects of plant invasion and landscape modification on native communities. Divers. Distrib. 20, 626-639 (2014).

54. Mason, T. J. \& French, K. Management regimes for a plant invader differentially impact resident communities. Biol. Conserv. 136, 246-259 (2007).

55. Sullivan, J. J., Timmins, S. M. \& Williams, P. A. Movement of exotic plants into coastal native forests from gardens in northern New Zealand. N. Z. J. Ecol. 29, 1-10 (2005).

56. R Core Team. R: A Language and Environment for Statistical Computing. (2019).

57. Zuur, A., Ieno, E., Walker, N., Saveliev, A. \& Smith, G. Mixed Effects Models and Extensions in Ecology with R (Springer, 2009).

\section{Acknowledgements}

This project was funded by the Australian Government's Department of the Environment and Energy (administered by the Department of Industry, Innovation and Science), as part of its "Improving Your Local Parks and Environment" program, with the aim of generating baseline data for long term monitoring of vegetation responses to release of a biocontrol agent (Kordyana brasiliensis) on Tradescantia fluminensis (https://research. csiro.au/wandering-trad/progress-dandenong/). We thank the Community Weeds Alliance of the Dandenongs (especially Bill and Jan Incoll) for assistance with locating field sites and plant species identification. Louise Morin, Isabel Zeil-Rolfe and two anonymous reviewers provided valuable comments on the earlier versions of this manuscript.

\section{Author contributions}

L.S.O.: conceptualization, formal analysis, writing_original draft; F.D.P.: conceptualization, writing—reviewing and editing; B.G.: conceptualization, methodology, investigation, writing-reviewing and editing, supervision; project administration.

\section{Funding}

This project was funded by the Australian Government's Department of the Environment and Energy (administered by the Department of Industry, Innovation and Science), as part of its "Improving Your Local Parks and Environment" program, with the aim of generating baseline data for long term monitoring of vegetation responses to release of a biocontrol agent (Kordyana brasiliensis) on Tradescantia fluminensis (https://research. csiro.au/wandering-trad/progress-dandenong/).

\section{Competing interests}

The authors declare no competing interests.

\section{Additional information}

Supplementary Information The online version contains supplementary material available at https://doi.org/ 10.1038/s41598-021-98667-5.

Correspondence and requests for materials should be addressed to L.S.O.

Reprints and permissions information is available at www.nature.com/reprints.

Publisher's note Springer Nature remains neutral with regard to jurisdictional claims in published maps and institutional affiliations.

Open Access This article is licensed under a Creative Commons Attribution 4.0 International License, which permits use, sharing, adaptation, distribution and reproduction in any medium or format, as long as you give appropriate credit to the original author(s) and the source, provide a link to the Creative Commons licence, and indicate if changes were made. The images or other third party material in this article are included in the article's Creative Commons licence, unless indicated otherwise in a credit line to the material. If material is not included in the article's Creative Commons licence and your intended use is not permitted by statutory regulation or exceeds the permitted use, you will need to obtain permission directly from the copyright holder. To view a copy of this licence, visit http://creativecommons.org/licenses/by/4.0/.

(C) The Author(s) 2021 